\title{
GLYCOGEN DISEASE
}

\author{
BY \\ S. VAN CREVELD \\ From the Paediatric Clinic of the Municipal University of Amsterdam, The Netherlands
}

(RECEIVED FOR PUBLICATION JULY 7, 1951)

\section{Two Early Cases of Glycogen Disease}

In June, 1928, at the meeting of the Dutch Paediatric Society, I read a paper on 'A Particular Disturbance in the Carbohydrate Metabolism in Childhood ', in which were reported observations on a boy whose metabolism showed peculiar disturbances. The mother had noticed that shortly after birth the baby's weight increased excessively and the abdomen became progressively larger. At the age of 8 months laparotomy was performed to determine the nature of the abdominal tumour. A very large, smooth liver was found but no biopsy was made.

In 1927, when the boy was 7 years old, I was able to make further investigations. At that time he was slightly stunted in growth, but much too heavy and gave the impression of a patient suffering from adiposogenital dystrophy. The liver was greatly enlarged; the spleen could not be felt. In the day specimen of urine, taken while the boy was on the ordinary hospital diet, neither sugar nor urobilin could ever be found, but acetone was often present. In a fasting condition the urine nearly always contained much acetone; in addition a considerable quantity of $\beta$-oxybutyric acid was frequently found. Radiographs of the bones of the hand revealed a severe delay in ossification (hepatic infantilism). Moreover, in the fasting condition marked hypoglycaemia was always present without any other abnormal symptoms. The mental development was normal. After the ingestion of 30 to $50 \mathrm{~g}$. of glucose, fructose, or galactose sugar was never excreted in the urine, even when the test was repeated within a few hours. Ketonuria, present on fasting, often disappeared slowly during these tests. After the ingestion of glucose the blood sugar curve was biphasic. Further, it was found that after an adrenaline injection there was a slight elevation of the blood sugar, but simultaneously a markedly increased ketosis was noted and a decrease of the respiratory quotient. From this we concluded that the injection of adrenaline caused in this patient a markedly increased combustion of fat, probably because he was unable to react normally to the injection with a mobilization of glycogen. Finally the boy proved to be hypersensitive to very small quantities of insulin. For this reason and because of the presence of acetone in the urine it was thought that hyperinsulinism could be excluded. From these and other findings I concluded in 1927 that this was a condition, hitherto unknown, which showed an accumulation of carbohydrates in the liver and perhaps in the muscles in the form of glycogen, which could be mobilized only with great difficulty. Consequently the patient was constantly in a metabolic condition in which carbohydrates were difficult to mobilize. In this way the hypoglycaemia and the acetonuria could be explained, as well as the boy's preference for bread.

Just over a year after we published these conclusions the anatomical proof for our hypothesis was supplied by von Gierke (1929) and the chemical proof by Schonheimer (1929) in the necropsy findings on two children who, it had been recorded, during life also had had marked enlargement of the liver, but in whom hardly any metabolic examinations had been performed. In these children von Gierke (1929) found, apart from enlargement of the liver, enlarged kidneys, due to an accumulation of glycogen which could only be mobilized with great difficulty. On the basis of these findings he called this condition hepatomegalia glycogenica.

Pompe (1930) was the first to describe an enormous hypertrophy of the heart muscle due to glycogen accumulation, which he called cardiomegalia glycogenica.

It was several years before similar clinical and pathological descriptions penetrated into the literature of other countries. In 1933, at the third international paediatric congress in London, three 
brothers were demonstrated suffering from cirrhosis of the liver without enlargement of the spleen. On this occasion I doubted this diagnosis and thought that probably in all three cases a glycogen liver was present, and as such the cases were later described.

In 1932 I observed a second case, a girl, then 5 years old; at the clinical and metabolic examination she showed features which corresponded with those found in the boy.

In 1933, after the researches of Cori and Cori (1931), we were able to obtain a better insight into the abnormal behaviour of both our patients with regard to their reaction to the injection of adrenalin. The absence of an initial blood sugar elevation after the injection was particular evidence of the immobilization of glycogen in the liver. The absence of the normal elevation of the lactic acid content in the blood, which occurs after the injection of adrenalin indicated an insufficient mechanism for mobilizing muscle glycogen, according to Cori and Cori (1931) and confirmed by Stetten (1946). Other metabolic disorders found at that time in both our patients were raised blood glycogen and hypercholesterinaemia. Discussing the differential diagnosis, the case described by Parnas and Wagner (1922) was referred to. Their patient showed a marked hypoglycaemia on fasting, without any symptoms, but always accompanied by acetonuria. The liver was enormously enlarged and the child showed symptoms of endocrine disturbance. In this case Parnas and Wagner (1922) had observed that, after the ingestion of various sugars there was hyperglycaemia and glycosuria with disappearance of the ketonuria, and for these and other reasons Parnas and Wagner (1922) assumed that in their case the liver no longer was able to convert sugar into glycogen. Later this patient developed into a case of diabetes mellitus. The possibility of cirrhosis of the liver and of a fatty liver, and of the syndrome of Mauriac (1930) had also to be considered in our cases. Arguments against the diagnosis of cirrhosis of the liver were particularly the absence of an enlarged spleen in both our patients and the fact that various liver function tests showed no abnormalities. The urine of the second case (the girl) showed a weakly positive urobilin reaction which appeared to indicate that the liver, in addition to glycogen accumulation, showed slight cirrhotic changes.

Kramer, Grayzel and Solomon (1935) were the first to indicate the possibility that a greatly enlarged liver combined with certain metabolic disorders might also be caused by a marked fatty infiltration of the liver. One of their cases showed a greatly enlarged liver, marked hypoglycaemia and no increase of the blood sugar after adrenalin injection. In this case, however, the hypercholesterinaemia and the ketonuria were absent, an absence which, with that of glycosuria after the ingestion of a large quantity of carbohydrates, indicated that the patient of Kramer et al. (1935) was able to utilize sugar.

Both our patients showed a complex of symptoms which differed from the symptoms observed in other patients with chronic disease of the liver. This conception was supported by the description of some cases of glycogen liver disease in which the diagnosis had been confirmed by necropsy or by biopsy in which a clinical and biochemical picture was found that was practically identical with that of both our patients. Since then some cases of cirrhosis of the liver in children have been described where some of the symptoms of glycogen liver disease were present. However, the presence of an enlarged spleen militated against the diagnosis of glycogen liver disease; moreover, at necropsy in some of these cases the liver proved to contain hardly any glycogen.

\section{Differential Diagnosis}

As dissociation of the disturbances in the liver function is well known, we could expect that the series of cases of glycogen liver disease described in the literature, would show a varying intensityco of some of the symptoms. And indeed, this could be seen during the further observation of both our patients and in certain others also. The pathological picture is not always the same, and the quantity of fat or connective tissue, which is stored with glycogen, shows variations; for example, much fat was present in the first case of von Gierke (1929) and in the cases of Krakower (1936). (Here it is useful to recall the name hépatomégalies polycoriques proposed by Debré (1947) as a general name for an enlargement of the liver caused by an accumulation of glycogen or fat, or of both substances.) In our first patient the parents were consanguineous, a feature which has been observed by others in cases of glycogen disease. Moreover frequently more than one case of glycogen liver disease (or glycogen heart) has been observed in the same family (Abramson and Kurtz, 1946).

As to the differentiation between glycogen liver disease and the syndrome of Mauriac (1930) we must stress the fact that this syndrome is frequently found in children with diabetes mellitus some months or years after the beginning of insulin treatment. Some years ago Houet (1947) reviewed 28 cases from the literature and two observed by himself. This syndrome is characterized by arrest of growth, hepatomegaly with swelling of the 
abdomen but without splenomegaly and ascites. For the differential diagnosis of glycogen liver disease the history is very important, but certain differences exist between the biochemical symptoms in both conditions.

The first clinical and pathological description of glycogen disease was followed by a large number of cases, mostly of hepatomegalia glycogenica, and some cases of cardiomegalia glycogenica. Besides this we find a number of cases with enlargement of more than one organ, due to accumulation of glycogen. We have already demonstrated that metabolic disturbances are found only in the hepatic form of the disease. In differentiating between this and other forms of glycogen disease (especially enlargement of the heart due to an accumulation of glycogen) a biopsy of the muscle can be of help, as the fibres of the striated muscles show a characteristic vacuolar structure without general enlargement.

\section{Cardiomegalic Glycogen Disease}

Wagner (1947) has recently described an increased glycogen content of the leucocytes in glycogen liver disease, a finding which should help greatly in diagnosis.

The diagnostic difficulties in the recognition of the cardiomegalic type of glycogen disease are much greater than in those of the hepatomegalic type. In the hepatomegalic form the disturbance of hepatic glycogenesis and glycogenolysis is responsible for an important part of the biochemical findings. As far as can be ascertained, these laboratory findings are absent in cases of cardiomegalia glycogenica, but it is probable that there is one common cause for the storage of glycogen in heart and liver. One of the arguments in favour of this hypothesis is that in both forms of the disease the accumulation of glycogen is not restricted to the organ which shows a visible enlargement, though in cases of hepatomegalia glycogenica the enlargement of the liver is predominant, and in cardiomegalia glycogenica, the heart enlargement. In the cardiomegalic type the accumulation of glycogen in the striated muscles is stressed, and they are sometimes equally enlarged. At present no other diagnostic test is available by which cardiomegalia glycogenica can be diagnosed during life, and in doubtful cases we have to rely upon the appearance at biopsy of the vacuolar structure of the skeletal muscle fibres.

Though less frequently than in the hepatomegalic form, more than one case of the cardiomegalic type of glycogen disease occasionally occurs in one family.

The clinical symptoms observed in a number of cases have already been mentioned in an earlier paper (van Creveld, 1939). In nearly all cases of glycogen heart disease diagnosed with certainty the children died between the ages of 4 months and 1 year, some of them earlier. This has remained constant, as appears from publications of Giampalmo (1944, 1949) and of di Sant Agnese, Andersen and Mason (1950).

The diagnosis of glycogen heart disease can be made only on certain limited clinical, pathological and chemical data. The clinical symptoms are few. The cases are nearly always young babies who do not thrive, show attacks of dyspnoea and sometimes of cyanosis during feeding. In some cases the dyspnoea and cyanosis have occurred suddenly, shortly before death. Physical examination usually shows the heart to be grossly enlarged, and the heart sounds to be normal. Sometimes there is a soft systolic murmur at the apex. The liver shows no or only a slight enlargement, although the spleen is sometimes palpable. In various cases impaired percussion with increased bronchophony and rhonchi were heard, especially over the left part of the thorax. The immediate cause of death is always acute heart failure, usually complicated by bronchopneumonia.

In antero-posterior radiographs the heart has been seen to be greatly enlarged in all directions, accompanied by signs of pulmonary collapse or emphysema. Electrocardiograms are of little use for the diagnosis of cardiomegalia glycogenica. Since the first description by Pompe (1930) little has been added to the pathological characteristics of the glycogen heart disease.

\section{Follow-up of the Two Early Cases}

Both our children are now grown up, aged respectively 30 and 24 years. Neither physical nor their mental development is retarded. The first patient is a well developed muscular man who shows no physical abnormalities. His height is now (July, 1951) $183 \mathrm{~cm}$., his weight $89 \mathrm{~kg}$. The urine and blood pressure are normal. He has been married for some years and has a son, about 1 year old, who seems to be perfectly normal. In the girl, who is married now, menstruation and secondary sexual development appeared at the normal time. She shows no physical abnormalities and is also well developed (in July, 1951, her height was $167 \mathrm{~cm}$., weight $65 \mathrm{~kg}$.). Some months ago she had an abortion, but we were unable to obtain further information about this. In both cases the liver is only just palpable, and has decreased in size since puberty (Fig. 1). Until he was 18 years old all the teeth of the boy were still deciduous, when gradually they were exchanged for permanent 


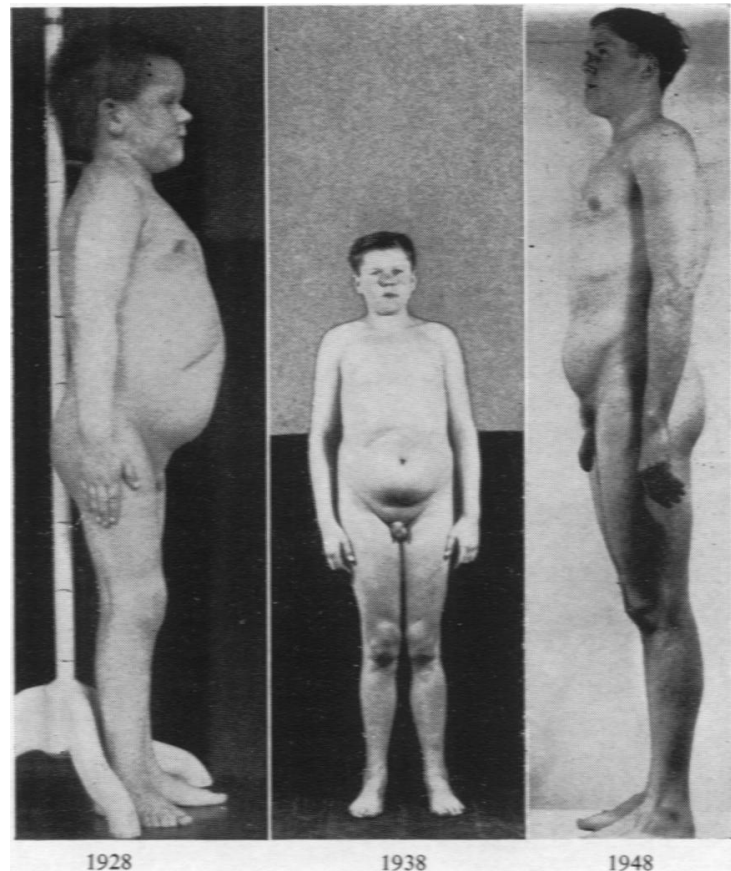

Fig. 1.-Photographs showing decrease in the size of the liver in our patient.

ones. In the girl the second dentition began at the normal time. On her first examination, when she was 5 years old, ossification was delayed, but in the course of some years this delay has disappeared, perhaps as a result of the anti-ketogenic diet which was prescribed at that time. In the boy the delay in ossification disappeared sooner; moreover for several years he has had a slight general osteoporosis.

Some authors are of the opinion that patients with glycogen liver disease show a special sensitivity to infections, but we have not seen this in our two patients.

In the course of years the biochemical symptoms of our patients have been studied at intervals. For many years we tried to influence the carbohydrate metabolism in the first patient, especially by prescribing a diet poor in fat and rich in carbohydrates. The general outlook of the young man has changed but little during and after puberty, and he has never shown alarming symptoms. His pronounced preference for bread has persisted for many years. After taking an extra quantity of sugar the urine never contained any glucose. The epiphyseal lines showed delayed fusion. The fasting blood sugar, which used to be extremely low, has increased in the course of years and for many years the fasting ketosis has disappeared.

In 1948 we performed some laboratory examinations (Table 1). The serum cholesterol and the blood glycogen levels were both slightly elevated.
The fasting blood sugar was rather low and adrenalin injection was not followed by an increase of the blood sugar nor of the lactic acid, and only a slight acetonuria was present. Formerly after adrenalin injection the absence of an increased blood sugar was always accompanied by a marked increase in the ketosis.

In July, 1951, we once more examined his reaction to the adrenalin injection. First the blood sugar, lactic acid and cholesterol were determined in venous blood on fasting, and then the changes in blood sugar and lactic acid after the subcutaneous injection of $0.6 \mathrm{mg}$. of adrenalin were observed. These results and those of the examination of the urine are summarized in Table 1. The fasting blood sugar content was now practically normal but did not change after adrenalin injection. The urine in the fasting condition did not contain acetone, but two hours after the adrenalin injection the acetone reaction was slightly positive. The lactic acid content of the blood showed a slight, temporary rise, and the serum cholesterol was only slightly elevated.

Two years ago, at appendicectomy, the muscle fibres in the wall of the removed appendix (Fig. 2) proved to contain large quantities of glycogen (stained according to Best by Dr. R. van Dam).

In the girl the most striking feature is the decreased size of the abdomen. Her mental and physical development are normal. The decrease in size of the liver has been gradual, as can be seen in Fig. 3 .

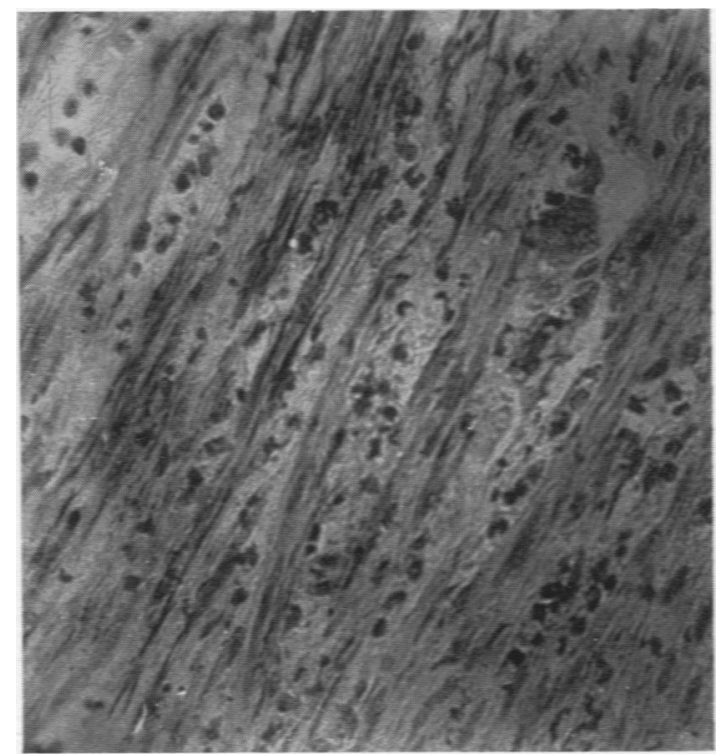

Fig. 2.-Section of wall of appendix showing glycogen in muscle fibres. 
TABLE 1

Hepatomegalia Glyoogenica in Case 1

\begin{tabular}{|c|c|c|c|c|c|c|c|c|c|}
\hline & & & & & & & & 1948 & 1951 \\
\hline Height (cm.) & .. & . & .. & .. & . & .. & . & 183 & 183 \\
\hline Weight (kg.) & .. & . & . & . & .. & .. & $\ldots$ & - & 89 \\
\hline \multicolumn{3}{|c|}{$\begin{array}{l}\text { Cephalin flocculation test } \\
\text { Takata-Ara test .. } \\
\text { Cholesterol level (mg.\%) } \\
\text { Blood glycogen level (mg. }{ }^{\circ} \text { ) }\end{array}$} & $\begin{array}{l}\cdots \\
\cdots \\
\cdots\end{array}$ & $\begin{array}{l}\cdots \\
\cdots \\
\cdots\end{array}$ & $\begin{array}{l}\cdots \\
\cdots \\
\cdots\end{array}$ & $\begin{array}{l}\cdots \\
\cdots \\
\cdots\end{array}$ & $\begin{array}{l}\cdots \\
\cdots \\
\cdots\end{array}$ & $\begin{array}{l}\text { slightly }+ \\
\frac{272}{19 \cdot 5}\end{array}$ & 233 \\
\hline
\end{tabular}

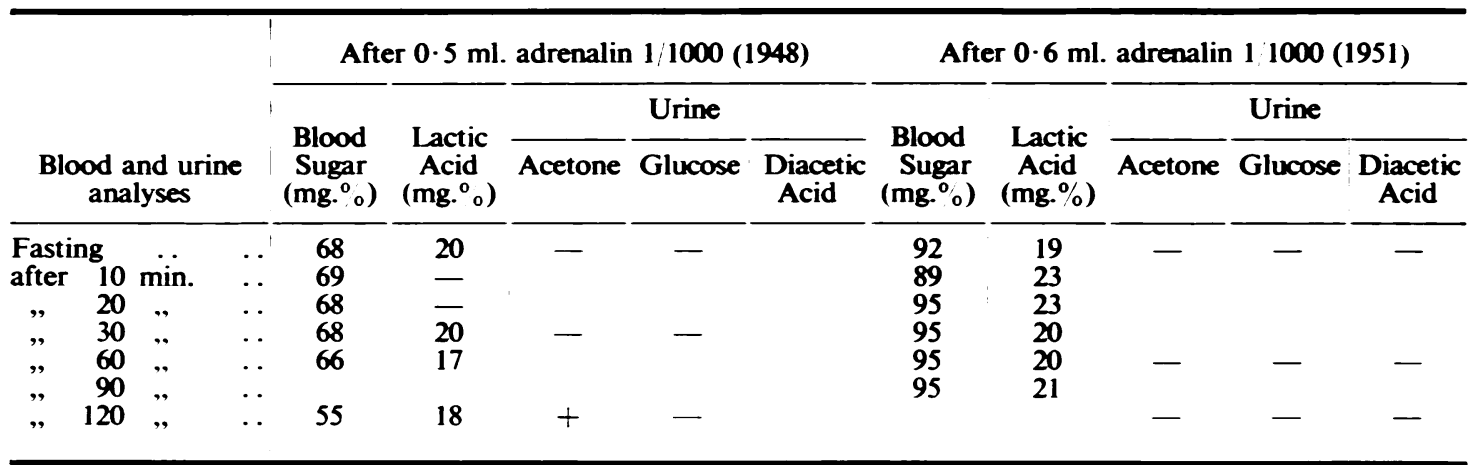

The urine in the fasting condition contains only a trace of acetone or none and she never has glycosuria. In Table 2 the results of laboratory tests performed since 1938 are summarized.

In 1938, at the age of 11 years, the liver was moderately enlarged and the spleen was just palpable. The urine in the fasting condition still had a positive reaction to acetone and urobilin. The blood cholesterol content was slightly increased. The fasting blood sugar content was normal and the glucose tolerance test showed a biphasic curve. The albumin-globulin ratio was normal, with the exception of a slightly increased globulin content. The abnormal biochemical findings were fewer in 1938 and to a lesser degree than when the patient was seen for the first time at the age of 5 years. In 1943, she contracted infectious hepatitis: the liver became greatly enlarged, the spleen remained just palpable. The urine showed a negative acetone reaction and a strongly positive urobilin reaction. The fasting blood sugar content was very low and after ingestion of glucose it showed a marked increase with a return to the very low original value within two hours. The serum cholesterol content was very low and the albuminglobulin ratio showed an extremely high globulin content.

In 1948 the patient was 21 years of age. The hepatomegaly had disappeared, the spleen remained just palpable. The urine on fasting did not contain acetone and only traces of urobilin. The serum cholesterol content and the serum proteins were approximately normal. Some liver function tests were almost normal. The fasting blood sugar content was normal again, but after adrenalin injection there was practically no response, and the reaction for acetone in the urine was slightly positive on only one occasion after adrenalin injection.

In July, 1951, when she was 24 years old, we were able to examine our patient once more. The urine contained a trace of urobilin, and, after adrenalin injection, only once a trace of acetone. The fasting blood sugar content was normal now, and after adrenalin injection it did not rise during the first half hour, and after that only slightly. The simultaneous determinations of lactic acid showed some slight variations. The serum proteins were normal. The blood glycogen content was increased. The glycogen content of the leucocytes, which, according to Wagner (1947), should also be increased considerably in glycogen liver disease was $4 \gamma$ per million leucocytes, thus at the upper limit of normal mean values.

It may be concluded that both patients still have some metabolic disorders similar to those found in the beginning of their disease. Changes in the blood sugar and lactic acid content after adrenalin injection are still absent though the fasting blood sugar has reached normal values. The fact that 


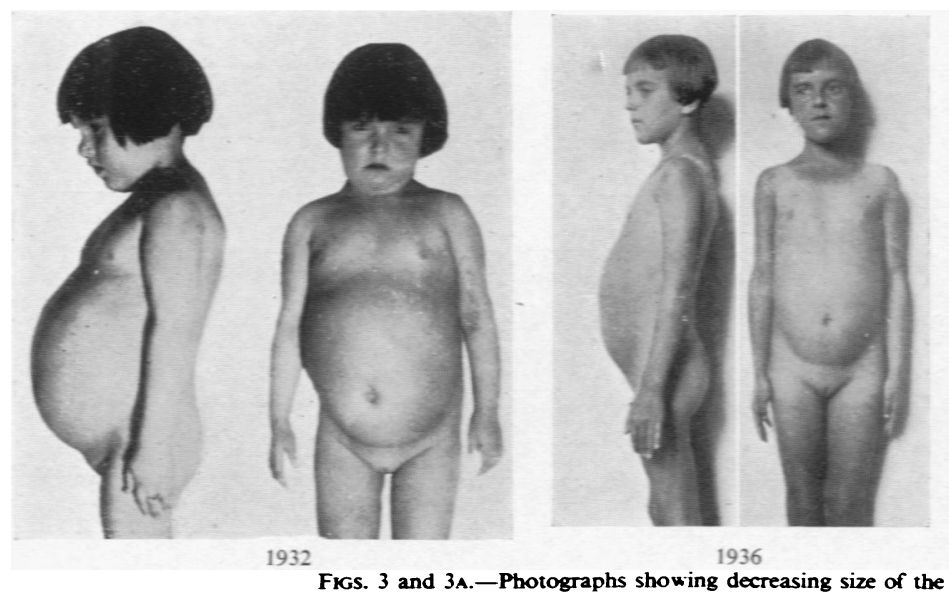

Figs. 3 and $3 A$ injection do not show both patients after adrenalin injection do not show
a normal glycaemic reaction at present points to a normal glycaemic reaction at present points to glucose. On the other hand, it appears that the quantity of glucose available for utilization is sufficient, probably by the increased fasting blood sugar content. The signs of an increased combustion of fat (ketonuria) in the fasting condition and after adrenalin injection are now absent or much smaller than formerly. The raised serum cholesterol has disappeared. It is probable that the mobilization of muscle-glycogen after adrenalin injection is still disturbed, as may be seen from the fact that the lactic acid content of the blood remains unchanged as

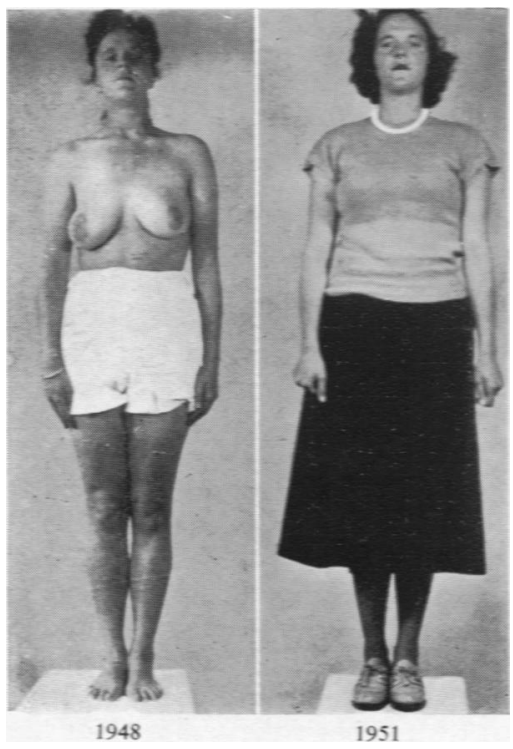

Fig. 3A. well.

From these observations in two cases of glycogen liver disease, which we were able to follow up for so many years, it appears that the prognosis is not necessarily unfavourable. In not one case of glycogen liver disease have we seen the transition into diabetes mellitus observed in the case of Parnas and Wagner (1922).

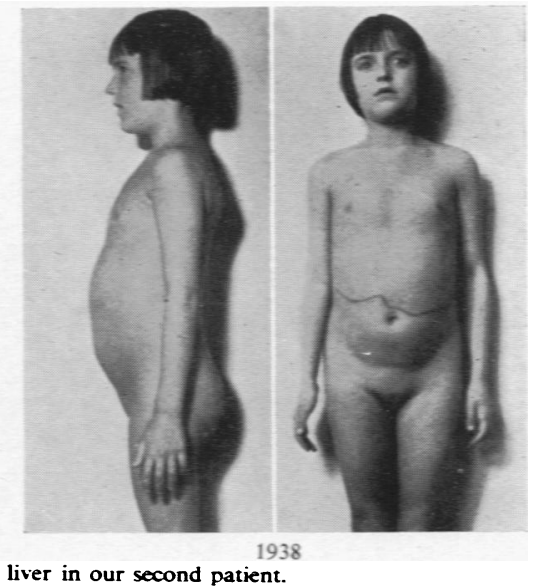

Aetiology

In the course of years the aetiology as well as the therapy of glycogen disease have frequently been discussed. To explain the aetiology of glycogen liver disease the problems concerned with glycogen metabolism in the liver and other organs must first be considered. Formerly the breaking down of glycogen in the liver was ascribed solely to the presence of an amylase. It was astonishing to find glycogen storage in the liver (and other organs) in glycogen disease, though glycogenase could be demonstrated. By the investigations of Cori and Cori (1931), de Duve (1945) and others it has become clear that in glycogen disease the presence of amylase in the liver has little or no significance. In the breaking down of glycogen in the liver are processes of phosphorylization partly analogous to those which occur in the muscles. Until recently it was impossible to detect a disturbance in one of these processes in glycogen disease, though the hypothesis that such a disturbance would be present had been expressed several times. One of the difficulties is that the material has to be examined immediately after a biopsy or after death. However, quite recently Mrs. Cori made a very important discovery which was reported to me by Prof. A. F. Hartmann, of St. Louis. In a typical case of glycogen disease in a baby she examined the composition of the liver with regard to its metabolism. She was able to demonstrate that the glycogen was quite normal. The glycogen in glycogen storage disease is identical in chemical structure with normal glycogen. Furthermore the concentration of all kinds of enzymes involved in the phosphorylization processes was normal, but the specific phosphatase of glucose-6phosphate was either entirely lacking, or was present in only a very small quantity. This could 
TABLE 2

Hepatomegalia Glycogenica in Case 2

\begin{tabular}{|c|c|c|c|c|c|c|c|c|c|c|}
\hline \multirow[b]{2}{*}{ Height $(\mathrm{cm})}$. & \multirow[b]{2}{*}{$\cdots$} & \multirow[b]{2}{*}{. } & \multirow{2}{*}{$\frac{1938}{125}$} & \multirow[t]{2}{*}{$1943^{*}$} & \multicolumn{3}{|c|}{1948} & \multicolumn{3}{|c|}{1951} \\
\hline & & & & & \multicolumn{3}{|c|}{167} & \multicolumn{3}{|l|}{167} \\
\hline Weight (kg.) & $\cdots$ & & 26 & & \multicolumn{3}{|c|}{$63 \cdot 3$} & \multicolumn{3}{|l|}{65} \\
\hline $\begin{array}{l}\text { Proteins }(\%) \\
\text { Total } \quad \ldots \\
\text { Albumin } \ldots \\
\text { Globulin .. } \\
\text { Fibrinogen }\end{array}$ & $\begin{array}{l}\cdots \\
\cdots \\
\cdots \\
\cdots\end{array}$ & $\begin{array}{l}\cdots \\
\cdots \\
\cdots \\
\cdots\end{array}$ & $\begin{array}{l}\text { in plasma } \\
7 \cdot 62 \\
4 \cdot 72 \\
2 \cdot 55 \\
0 \cdot 35\end{array}$ & $\begin{array}{l}\text { in plasma } \\
9.03 \\
3 \cdot 5 \\
5 \cdot 17 \\
0.36\end{array}$ & \multicolumn{3}{|c|}{$\begin{array}{l}\text { in serum } \\
6 \cdot 06 \\
3 \cdot 99 \\
2 \cdot 07 \\
-\end{array}$} & \multicolumn{3}{|c|}{$\begin{array}{c}\text { in serum } \\
5 \cdot 9 \\
3 \cdot 73 \\
2 \cdot 17 \\
-\end{array}$} \\
\hline \multicolumn{3}{|c|}{$\begin{array}{l}\text { Cephalin flocculation-test } \\
\text { Takata-Ara test } \\
\text { Glycogen in blood (mg. } \% \text { ) } \\
\text { Glycogen per million of } \\
\text { leucocytes }(\gamma) \ldots\end{array}$} & - & + & \multicolumn{3}{|c|}{+} & \multicolumn{3}{|c|}{$21 \cdot 2$} \\
\hline \multirow{2}{*}{\multicolumn{3}{|c|}{ Blood sugar curve }} & & & \multirow{2}{*}{\multicolumn{3}{|c|}{$\begin{array}{l}\text { After } 0.75 \mathrm{ml} . \\
\text { Adrenalin 1/1000 } \\
(\mathrm{mg} \% \%)\end{array}$}} & \multicolumn{3}{|c|}{ After $0.5 \mathrm{ml}$. Adrenalin $1 / 1000$} \\
\hline & & & $\begin{array}{l}\text { After } 30 \mathrm{~g} . \\
\text { Glucose } \\
\text { (mg.\%) }\end{array}$ & $\begin{array}{l}\text { After } 50 \mathrm{~g} . \\
\text { Glucose } \\
\text { (mg.\%) }\end{array}$ & & & & & $\begin{array}{l}\text { Blood } \\
\text { Sugar } \\
\text { (mg.\%) }\end{array}$ & $\begin{array}{l}\text { Lactic } \\
\text { Acid } \\
\text { (mg.\%) }\end{array}$ \\
\hline 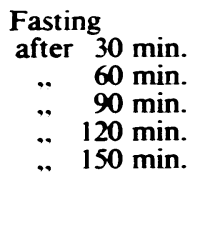 & $\begin{array}{l}\cdots \\
\cdots \\
\cdots \\
\cdots\end{array}$ & $\begin{array}{l}\because \\
\because \\
\cdots \\
\cdots\end{array}$ & $\begin{array}{r}86 \\
161 \\
100 \\
141 \\
123 \\
119\end{array}$ & $\begin{array}{r}46 \\
140 \\
184 \\
170 \\
97 \\
40\end{array}$ & $\begin{array}{l}\text { After } \\
\text { " } \\
\Longrightarrow \\
\Longrightarrow \\
, "\end{array}$ & $\begin{array}{l}10 \mathrm{~min} . \\
20 \mathrm{~min} . \\
30 \mathrm{~min} . \\
60 \mathrm{~min} . \\
90 \mathrm{~min} . \\
120 \mathrm{~min} . \\
150 \mathrm{~min} .\end{array}$ & $\begin{array}{l}84 \\
82 \\
88 \\
86 \\
92 \\
95 \\
91 \\
83\end{array}$ & $\begin{array}{l}\text { After } 15 \mathrm{~min} . \\
\text {, } 30 \mathrm{~min} . \\
, \quad 60 \mathrm{~min} . \\
, \quad 90 \mathrm{~min} .\end{array}$ & $\begin{array}{r}92 \\
84 \\
89 \\
100 \\
100\end{array}$ & $\begin{array}{l}18 \\
16 \cdot 9 \\
23 \cdot 4 \\
16 \cdot 7 \\
15 \cdot 8\end{array}$ \\
\hline
\end{tabular}

Urine

Acetone (fasting)

After adrenalin injection

$\begin{array}{lll}\text { Acetone } & . . & . \\ \text { Diacetic acid } & . . & \text {. }\end{array}$

$\begin{array}{lll}\text { Urobilin } & . . & . \\ \text { Sugar } & & \end{array}$

Sugar $\quad . . \quad \ldots$

$\begin{array}{ll} & \\ \cdots & + \\ \cdots & + \\ \cdots & -\end{array}$

\begin{tabular}{llllllll}
\hline Hepatomegaly & $\cdots$ & $\cdots$ & + & ++ & Absent & Absent \\
Splenomegaly & $\cdots$ & $\cdots$ & + & + & Slightly palpable & Slightly palpable \\
\hline
\end{tabular}

* In 1943 the patient had infectious hepatitis.

be the explanation of the disturbance in glycogenolysis.

Sufficient arguments exist in favour of the conception that in glycogen disease hormonal factors are also of great importance. Recent researches have stressed the possible significance of A.C.T.H. in glycogen disease. On this subject and on the possible part played by the pituitary gland in general in glycogen disease, the case of glycogen liver disease in a girl 3 years old is interesting. In the urine of this child, Dr. Dingemanse and Dr. Huis in 't Veld found a very low value for the 17-ketosteroid excretion $(0.9$ and $1.2 \mathrm{mg} . / 24$ hours). An A.C.T.H. preparation, 'cortrophin', of which the injection of $1 \mathrm{mg}$. in a patient with a strong eosinophilia had caused a marked diminution in eosinophils, was given in small amounts for two days (0.5 mg. four times a day) and caused a significant decrease in the glycogen of the leucocytes. Before the injections the glycogen content was increased $(7 \cdot 3,6 \cdot 6$, and $5.9 \gamma$ per million leucocytes); after the injections it decreased to 3.2 and $2 \gamma$. According to Wagner the normal maximal value is $4.43 \gamma$ per million leucocytes. It cannot be ascertained whether under the influence of A.C.T.H. more glycogen 
has been stabilized as glycogen or that more glycogen has been used by the metabolic process.

\section{Treatment}

At present no established therapy in glycogen disease exists. Administration of amylase or of hormone preparations has not given any result. The combination of hypoglycaemia and acetonuria has suggested the prescription of a diet rich in carbohydrates and poor in fat. The preference for carbohydrates (bread, potatoes) of the patients sometimes gives rise to such symptoms as nausea and fatigue. The oral ingestion of choline, as prescribed to one of our patients after the publications of Best, may have some influence on the ketosis, especially when there is reason to believe that the liver contains a great deal of fat as well as glycogen. Bridge and Holt (1945) have recommended that these patients should take an extra quantity of proteins in the evening in order to eliminate the detrimental consequences of an increased transformation of proteins into glycogen. Lowrey and Wilson (1949) recently observed a case of glycogen liver disease in a boy of 2 years, in whom the symptoms of hypoglycaemia could be favourably influenced by the administration of large quantities of proteins and small quantities of carbohydrates. Matheson (1949), like other investigators, observed in one case the quick disappearance of the ketonuria and reduction of the distended abdomen after giving bile salts. These therapeutic measures have no fundamental effect on the disease.

\section{Summary}

A short survey is given of the early history of glycogen disease. The diagnosis and differential diagnosis of the two principal types of the disease are discussed. The clinical course and the development of typical metabolic findings up to date are communicated of the two cases of the hepatomegalic type of the disease described by the author for the first time in 1928 and 1932 respectively.

\section{REFERENCES}

Abramson, H. and Kurtz, L. D. (1946). Amer. J. Dis. Child., 72, 510.

Bridge, E. M. and Holt, L. E., Jr. (1945). J. Pediat., $27,299$.

Creveld, S. van (1939). Medicine, Baltimore, 18, 1.

and Linde, H. M. van der (1939). Archives of Disease in Childhood, 14, 14.

Debré, R. (1947). 'Polycories.' Paris.

Duve, C. de (1945). 'Glucose, insuline et diabéte.' Paris.

Giampalmo, A. (1944). Policlin. infant., 12, 239.

- (1949). Arch. 'Maragliano', Patol. Clin., 4, 887.

Houet, R. (1947). Ann. paediatr., Basel, 168, 113.

Lowrey, G. H. and Wilson, J. L. (1949). J. Pediat., 35, 702.

Matheson, W. J. (1949). J. Pediat., 34, 537.

Sant 'Agnese, P. A. di, Andersen, D. H. and Mason, H. M. (1950). Pediatrics, Springfield, 6, 607. 402.

Stetten, De Witt (1946). J. Amer. med. Ass., 132, 373.

Wagner, R. (1947). Amer. J. Dis. Child., 73, 559.

\section{BIBLLGRAPHY}

For the literature till 1938 see Creveld, S. van (1939), loc. cit.:-

Antopol, W., Boas, E. P., Levison, W. and Tuchman, L. R. (1940). Amer. Heart J., $20,546$.

Chieff, A. and Nassi, L. (1948). Riv. Clin. pediat., 46, 631.

Cori, C. F. (1940). Endocrinology, 26, 285.

Cori, G. T. and Cori, C. F. (1943). J. biol. Chem., 151, 57.

Crawford, T. (1946). Quart. J. Med., 15, 285.

Gardner, E. and Simpson, K. (1938). Lancet, 1, 659.

Holt, L. E. Jr., Bass, M. H. and Wilson, S. J. (1950). Amer. J. Dis. Child., 79, 406.

Mason, H. H. and Andersen, D. H. (1941). Amer. J. Dis. Child., 61, 795.

Orsini, M. (1949). 'Glicogenosi.' Rome. 